\title{
A new species of Argulus from Kosi Bay, South Africa and distribution records of the genus
}

\author{
Annemarié Avenant-OldeWage
}

\begin{abstract}
Avenant-Oldewage, Annemarié. 1994. A new species of Argulus from Kosi Bay, South Africa and distribution records of the genus. Koedoe 37(2): 89-95. Pretoria. ISSN 0075-6458.

A new species of the fish ectoparasite Argulus i.e. A. kosus is described from Kosi Bay in South Africa. This species is characterised by deep antero-lateral depressions of the dorsal carapace which delimit a pronounced frontal region, scales are present on the mouth tube, varying numbers of sclerites are present on the maxillae, no flagella occur on the swimming legs nor any scales on the antennae. The shape of the respiratory areas are also typical for this species. A table of the distribution of the genus in South Africa and a map showing the localities, is also included.
\end{abstract}

Key words: Argulus, Kosi Bay, distribution.

Annemarié Avenant-Oldewage, Department of Zoology, Rand Afrikaans University, P.O. Box 524, Auckland Park, 2006 Republic of South Africa.

\section{Introduction}

The genus Argulus is widely distributed in both marine and freshwater habitats throughout Africa, and 32 different species have been described from this region (Rushton-Mellor 1994). In South Africa, work on this group was pioneered by Barnard (1955) with his descriptions of a number of species. Since his paper, no additional taxonomical paper appeared from this region, although a number of papers on other aspects of this genus has recently been published on the introduced Argulus japonicus (Kruger et al. 1983; Swanepoel \& Avenant-Oldewage 1992; Avenant-Oldewage \& Swanepoel 1993; Lutsch \& Avenant-Oldewage in press).

Despite extensive surveys since 1983 in rivers in the areas then known as Transvaal and northern Natal, Argulus japonicus was the only representative of this genus in South Africa and, at times, at catostrophic densities (Kruger et al. 1983). Recently, two specimens of an as yet undescribed species were found in Kosi Bay. These are described below.

\section{Materials and methods}

During July 1993, two adult females (Argulus sp.) were collected from the skin surrounding the dorsal fin of a strepie, Sarpa salpa Linn., at Kosi Bay in northern KwaZulu-Natal. It was fixed in Todd's fixative (Todd 1986). Prior to examination they were washed in running tap water, dehydrated in an ascending ethanol series to $70 \%$, and cleared in $90 \%$ lactic acid. They were studied with the aid of a Zeiss Lab 18 microscope with a drawing tube attachment.

The specimens are in the collection of the Albany Museum, Grahamstown, holotype no. RAU 2A and paratype RAU 2B

\section{Results}

Argulus kosus spec. nov.

\section{Description}

Adult female. General body shape ovoid (Figs. 1a \& b), carapace comprising $71 \%$ of total body length. Body length of largest individual $5,88 \mathrm{~mm}$. Body dorsally covered by a carapace with lobes extending to cover the fourth pair of legs. Sinus in carapace $19 \%$ of 

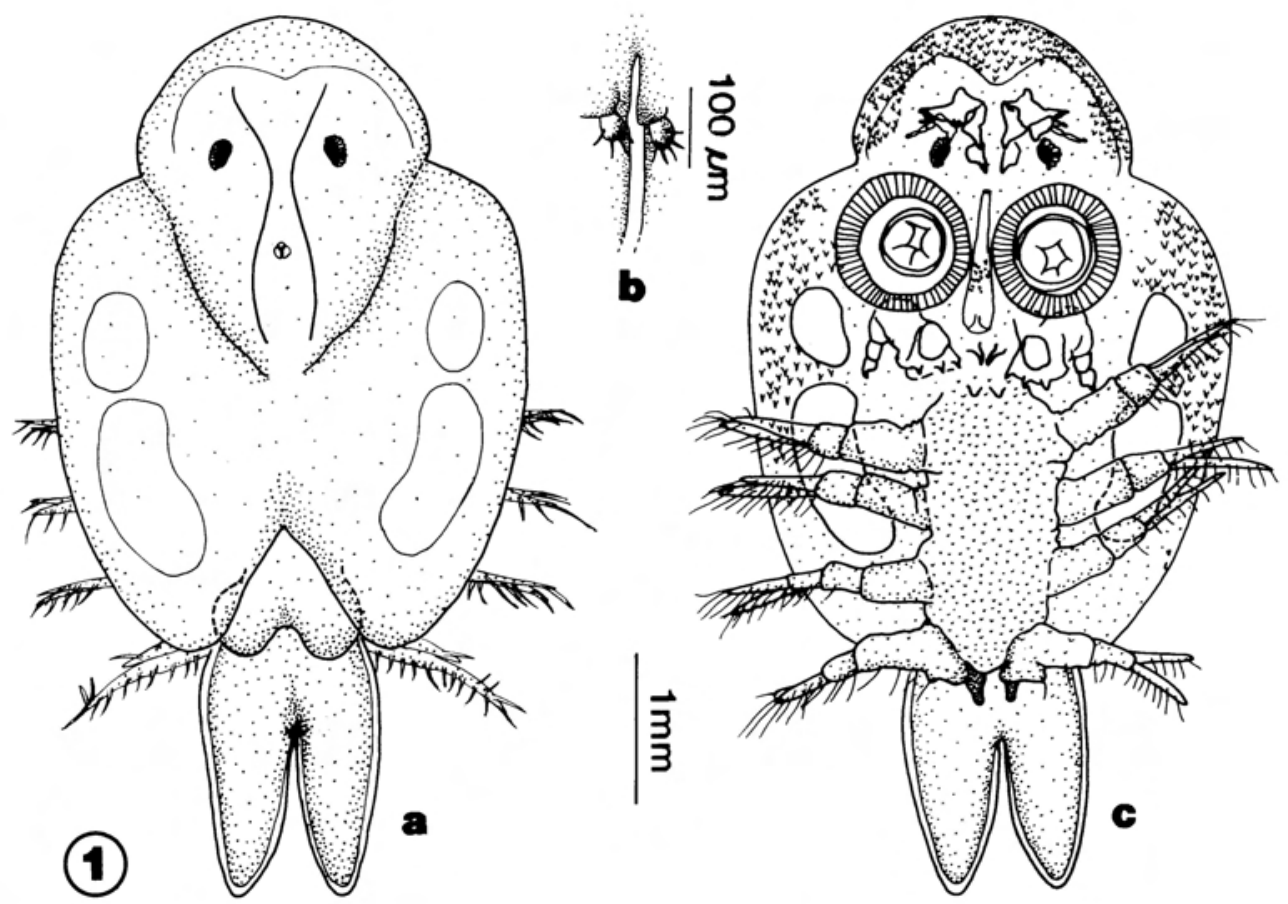

Fig 1. Argulus kosus spec. nov. (a) dorsal view, (b) furcal rami, (c) ventral view.

length of carapace and expose the third and fourth thoracic segments dorsally. A kidneyshaped lobe present on the fourth thoracic segment - the lobes thereof extending over the abdomen (Fig. 1a).

Compound eyes small, crescent-shaped, dark brown and present in the anterior third of the body. Distance between eyes almost equal to distance from lateral margin. Nauplius eye same distance from eyes as distance between eyes forming an equilateral triangle.

Colour in live specimens milky white with green tinge. Antero-lateral depressions pronounced forming broad, rounded frontal region.

Abdomen slender, anal sinus along $66 \%$ of its length to form two pointed lobes. Two furcal rami situated at base of anal sinus (Figs. 1a $\&$ b). Rami are simple rounded structures with three to four setae. Paired spermathecae situated anteriorly.

Ventral surface of carapace peripherally covered by numerous, regularly-arranged spines of similar size extending along two thirds of carapace (Fig. 1c). Paired respiratory areas on ventral surface, smaller respiratory area approximately half size of larger and located entirely anterior to large area, both oval, with non-indented outlines (Figs. 1a \& c).

Antennulae (Fig. 2a) comprising two sections; stout proximal part posessing large spines; slender distal part bearing setae. Proximal part bears a small hook-like anterior spine, a large hook-like terminal spine as well as a prominent medial spine. Proximal sec- 


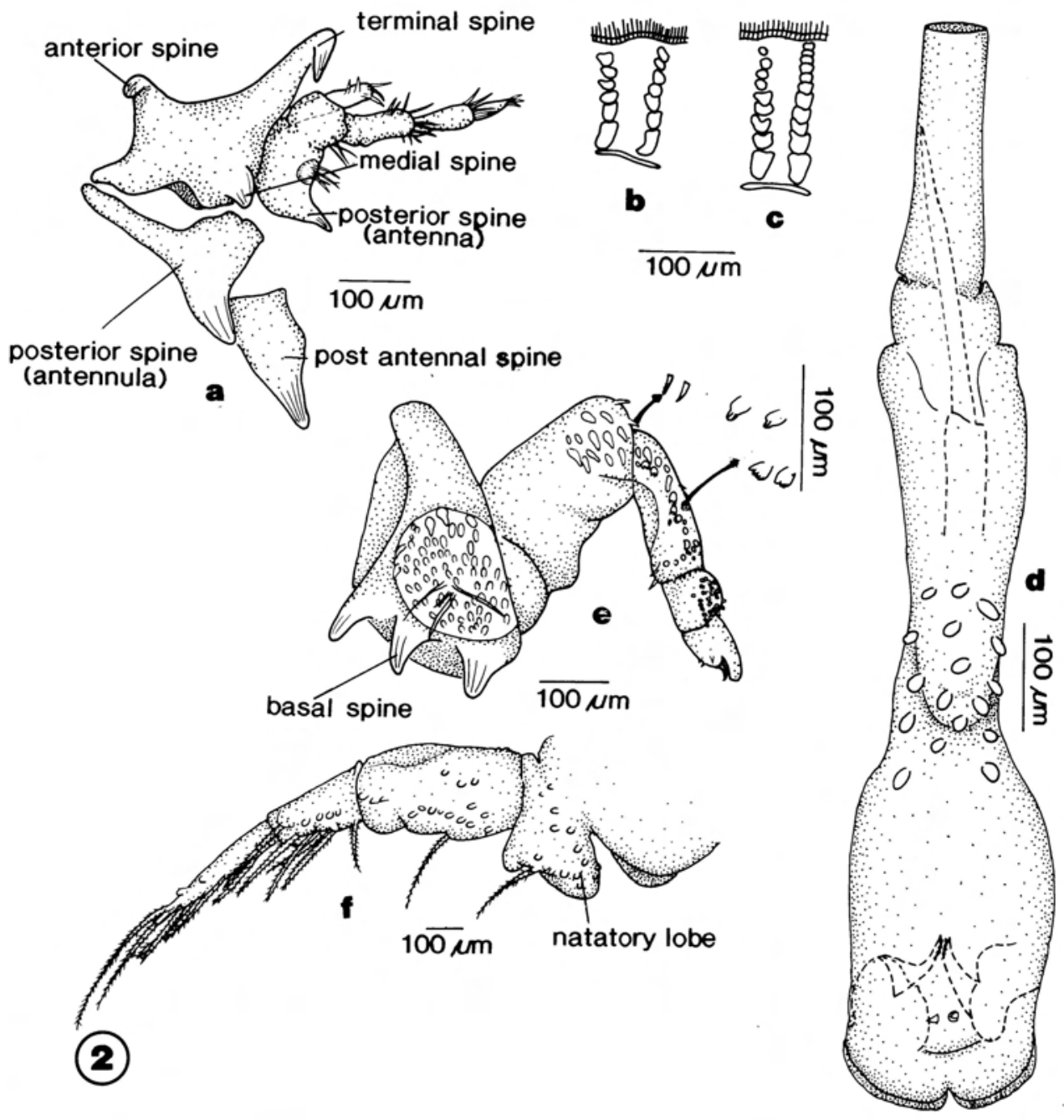

Fig. 2. Argulus kosus spec. nov. (a) antennula and antenna, sclerite rows on maxillula on (b) outer rim and (c) inner rim, (d) mouth tube and retractile spine, (e) maxilla, (f) fourth leg with natatory lobe.

tion extend beyond anterior spine and forms a triangular extension towards the midline. Distal tubular section extends beyond terminal spine and comprises of two parts; penultimate lacks setae, terminal segment with group of apical setae. Posterior spine with long triangular extension proximally and sclerotized spine posteriorly. Single well developed post-antennal spine. Antennae four segmented (Fig. 2a). Basal segment massive bearing posterior spine and numerous setae.
Distal three segments tubular bearing setae on their distal margins.

Maxillulae forming suckers (Fig. 1c) with sclerites acting as supporting rods in the sucker rim (Figs. 2b \& c). Although supporting rods is considered to be of taxonomic value in other Argulus species in A. kosus number as well as shape of sclerites vary dramatically with larger numbers of sclerites 
(9-11) on the inner and smaller numbers (6-7) on the outer margin (Figs, $2 b \& \mathrm{c}$ ).

Maxillae five segmented, basal segment with basal plate covered by simple scales and bearing tuft of setae centrally (Fig. 2e). Spines increasing in size, distally present on posterior surface of basal segment. Second to fourth segments with simple and pectinate scales. Terminal segment with a sharp claw and two blunt protrusions.

Retractile pre-oral spine and mouth tube (Fig. 2d) located between the maxillulae. Mouth tube slender twice as long as wide carrying simple scales basally, denticulate mandibles and so-called "labral" spines visible in cleared specimens.

Pair of accessory spines located between maxillae and pair of thoracic spines posterior to maxillae (Fig. 1c). First to fourth pairs of legs biramous and of near equal size, sympods consists of two podomeres. Endopods and exopods present on all legs, exopod on leg 3 consists of two parts. Endopods and exopods bear two rows of plumose setae each. Flagellum absent on all legs. Natatory lobe on fourth leg simple (Fig. 2f).

Minute, simple scales present on the area between legs as well as on the antero-proximal surface of leg 1 (Fig, Ic) and scattered on the sympod and natatory lobe of leg 4 (Fig. 2f).

Male unknown.

\section{Remarks}

Distinctive features of Argulus kosus are the deep antero-lateral depressions of the dorsal carapace which delimit a pronounced frontal region, the presence of scales on the mouth tube, the unstable number of sclerities on the maxillulae, the shape of the respiratory areas, the absence of flagella on the swimming legs as well as the absence of scales on the antennae.
Argulus kosus resembles A. capensis Barnard, 1955 as well as $A$. fryeri RushtonMellor, 1994, but it is clearly distinguishable from both. A. kosus differs from A. fryeri in the following unique features: flagella are absent on all legs, the shape of the natatory lobes as well as the respiratory areas differ, a hook-shaped anterior spine is present on the antennula, the shape of the posterior spine of the antennulae has a very long proximal extension; a bilobed structure is present on the dorsal surface of the fourth thoracic segment. Furthermore, the shape of the spines on the basal plate of the maxillae differ considerably from that of $A$. fryeri.

Argulus kosus differs from A. capensis in the general shape and number of sclerites on the maxillulae as well as the presence of a bilobed structure on the fourth thoracic segment.

\section{Argulus in South Africa}

Five species of Argulus have hitherto been recorded from South Africa i.e. A. belones van Kampen 1909, A. capensis Barnard, 1955, A. multipocula Barnard, 1955, A. japonicus Thiele, 1900 and the new A. kosus. The distribution of these are summarised in Table I and illustrated in Fig. 3. It is interesting to note from these data that only the introduced $A$. japonicus is present in numbers and distribution of any significance. The three species recorded by Barnard in 1955 has not been recorded since then and even in the case of the newly described Argulus kosus, only two specimens were found although 125 fishes were examined of which 37 were of the host species.

Kosi Bay is a misnomer, as this water body is connected to the sea to form an estuary that can be closed in by a sand bank, depending on the dominant wave climate and longshore current action. At such times temporary lakes form. A. kosus was found in one of these temporary lakes. 


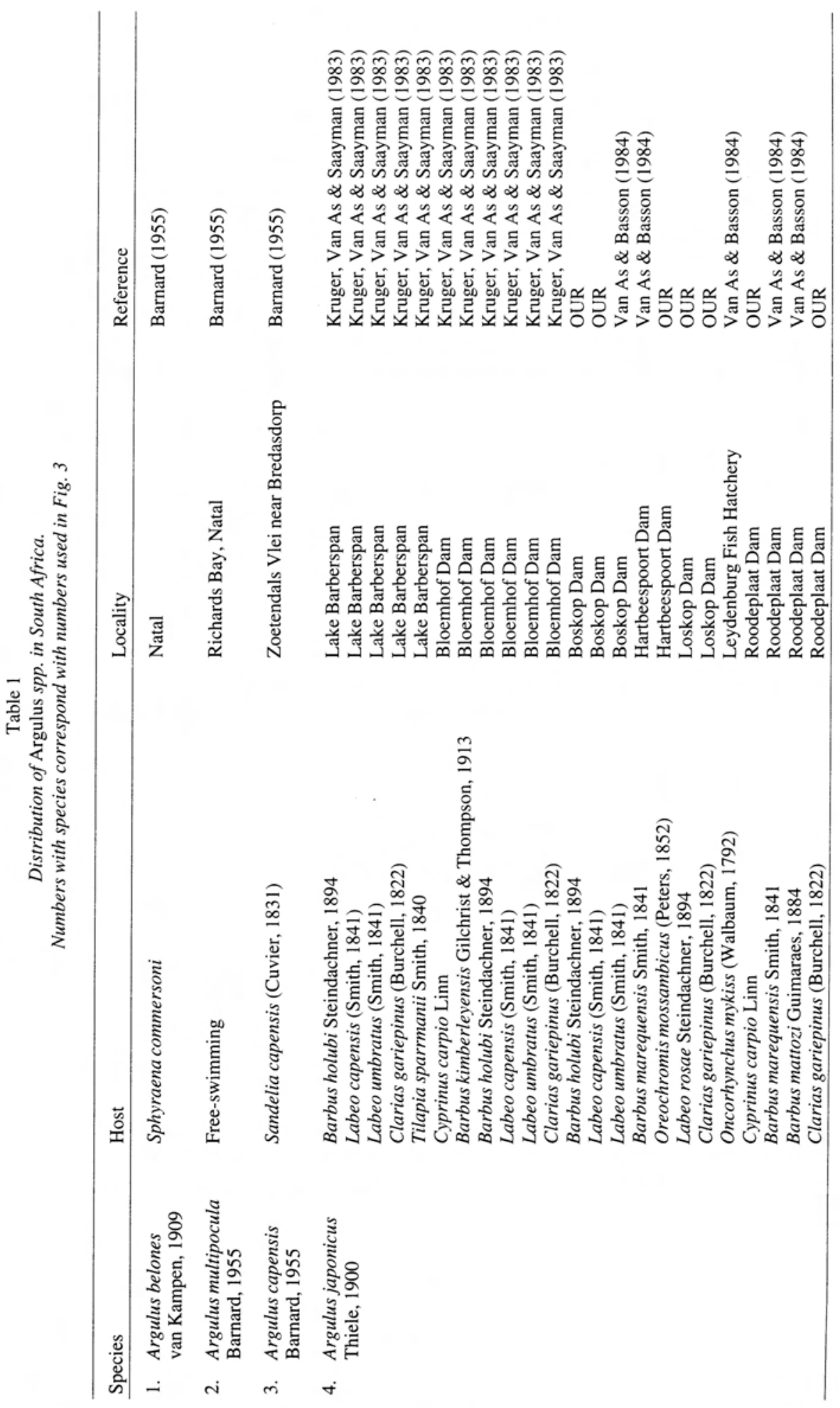




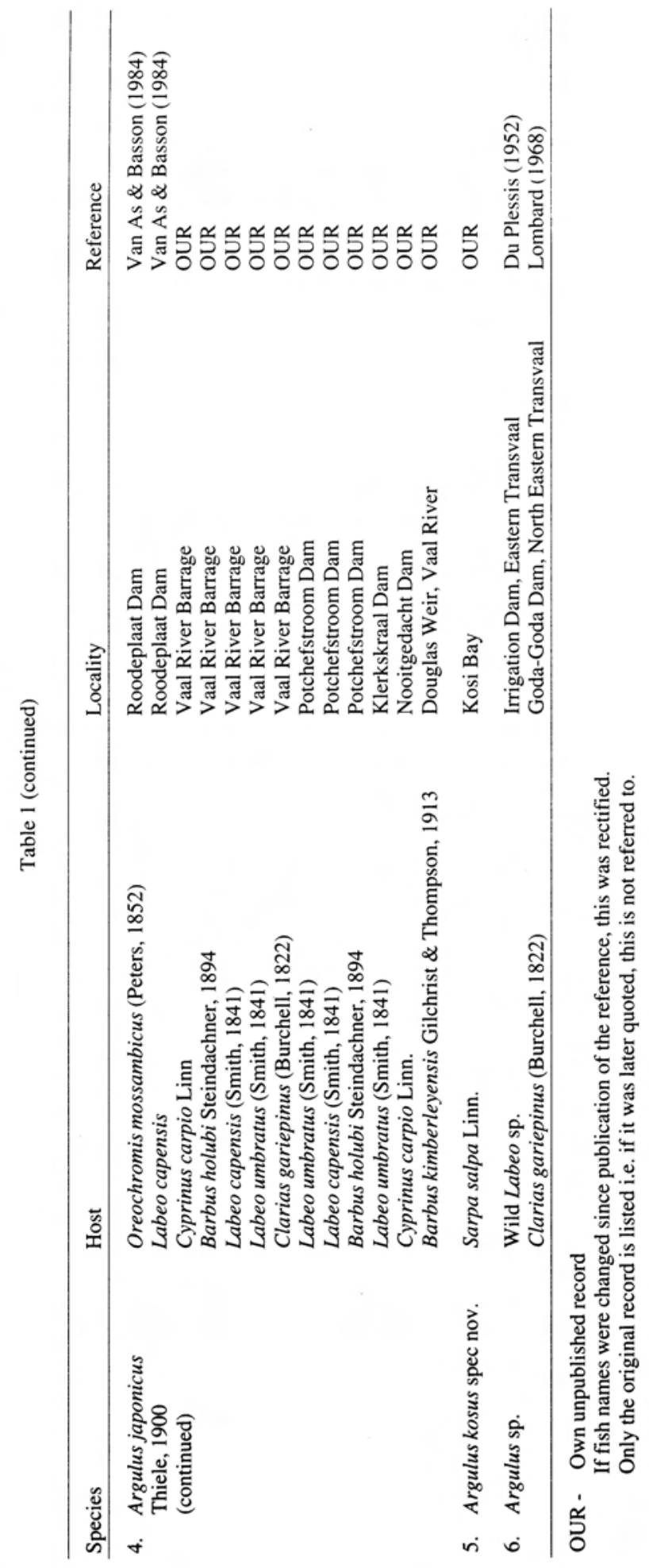




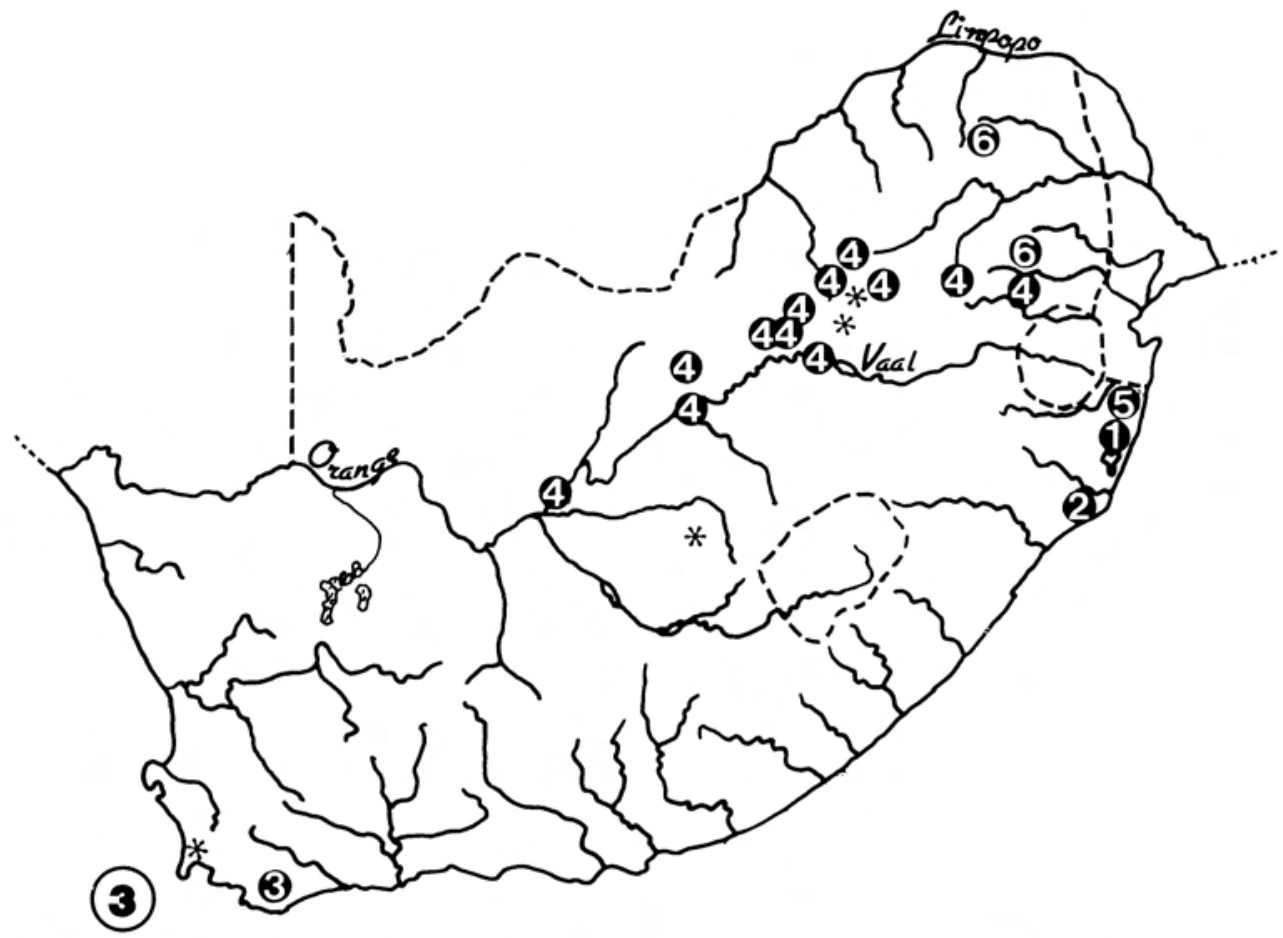

Fig. 3. Map of South Africa to show distribution of the genus Argulus $1=$ A. multipocula: $2=$ A. capensis;

$3=$ A. japonicus: $4=$ A. kosus: $5=$ Argulus species. Broken lines represent borders not formed by rivers, asterisks represent major cities. Numbers correspond with those in Table I.

\section{References}

Avinant-Ol.dewage, A. and J.H. Swanepolt. 1993. The male reproductive system and mechanism of sperm transfer in Argulus japonicus (Crustacea: Branchiura). Journal of Morphology 215: 51-63.

Barnard, K.H. 1955. South African parasitic Copepoda. Annals of the South African Museum 41: 223-312.

DU Plessis, S.S. 1952. Fish diseases in Transvaal. Limnological Society of South Africa, Symposium on African Hydrobiology and Inland Fisheries. Communication No 37. Publication No 6: 128-130.

Krugitr, I., J.G. van As and J.E. SaAyman. 1983. Observations on the occurrence of the fish louse Argulus japonicus, 1900 in the western Transvaal. South African Journal of Zoology 18(4): 408-410.

LOMBARD, G.L. 1968. A survey of fish diseases and parasites encountered in Transvaal. Newsletter of the Limnological Societv of South Africa 11: 2399.

Lutsch, E. And A. Avenant-Ol.dewage: (in press). The ultrastructure of the newly hatched Argulus japonicus Thiele, 1900 larvae (Branchiura). Crustaceana.

Rushton-Mtllor, S.K. 1994. The genus Argulus (Crustacea: Branchiura) in Africa: identification keys. Systematic Parasitology 28(1): 51-63.

Swanepoel, J.H. and A. Avenant-Oldiwage. 1992. Comments on the morphology of the pre-oral spine in Argulus (Crustacea: Branchiura). Journal of Morphology 212: 155-162.

ToDD, W.T. 1986. Effects of specimen preparation on the apparent ultrastructure of micro-organisms. Pp 87-100. In: ALidrich, H.C. AND W.T. TODD (eds.). Ultrastructure techniques for microorganisms. New York: Plenum Press,

van As, J.G. AND L. Basson. 1984. Checklist of freshwater fish parasites from southern Africa. South African Journal of Wildlife Research 14(2): 49-61. 